\title{
Application of the Kirkwood-Buff theory of solutions to acetonitrile + amide binary mixtures by using inversion procedure and regular solution theory
}

\author{
ANIL KUMAR NAIN \\ Department of Chemistry, Dyal Singh College (University of Delhi), New Delhi 110003 \\ e-mail: ak_nain@yahoo.co.in
}

MS received 17 September 2008; revised 23 March 2009

\begin{abstract}
The Kirkwood-Buff (K-B) integrals play an important role in characterizing the intermolecular interactions in liquid mixtures. These are represented by the $\mathrm{K}-\mathrm{B}$ parameters, $G_{\mathrm{AA}}, G_{\mathrm{BB}}$, and $G_{\mathrm{AB}}$, which reflect correlation between like-like and like-unlike species in the mixture. The K-B integrals of binary mixtures of acetonitrile (ACN) with formamide (FA), N,N-dimethylformamide (DMF), N-methylacetamide (NMA) and N,N-dimethylacetamide (DMA) at 298.15 K and at atmospheric pressure have been computed from the experimental data of ultrasonic speed and density. We have used the similar inverse procedure (as proposed by Ben-Naim) to compute the K-B Parameters of the mixtures, in which thermodynamic information on mixtures such as partial molar volumes, isothermal compressibility, and experimental data of partial vapour pressures are used. A new route has been incorporated by using regular solution theory in the computation of excess free energy for obtaining the partial vapour pressures of binary liquid mixtures. The low values of excess entropy $\left(S^{E} \approx 0\right)$ obtained for these mixtures indicate the applicability of regular solution theory to these mixtures. The results obtained regarding intermolecular interaction in all the four mixtures under study from this new procedure are in good agreement with those obtained from the trends exhibited by the excess functions of these mixtures.
\end{abstract}

Keywords. Kirkwood-Buff integrals; binary liquid mixtures; acetonitrile; amide; intermolecular interactions.

\section{Introduction}

Theoretical prediction of the physicochemical properties of multi-component liquid systems involves an interdisciplinary interest and proved to be an excellent qualitative and quantitative tool for elucidating the molecular structure and nature and extent of interactions in liquid systems. A large amount of experimental data exists, in the literature, on the physicochemical, thermodynamic, transport, acoustic and spectroscopic properties of multi-component liquid systems. ${ }^{1-10}$ But in contrast to this vast experimental work, there exist very few theoretical works on the elucidation of molecular structure and estimation of thermodynamic properties of liquid mixtures. Recently, researchers in this field have been focusing their interest more sharply on the molecular structure along with some representative macroscopic properties that serves to characterize it. ${ }^{11,12}$

Kirkwood and Buff ${ }^{13}$ theory of solutions relates the radial distribution functions of various molecular species in a mixture to the derivatives of the thermodynamic properties of the species. This is a general statistical mechanical theory of solutions which is applicable to all types of intermolecular interactions and is valid both classically and quantum mechanically. It is one of the most accepted theories of solutions that directly correlate the thermodynamic quantities with the solution structure without any assumptions. K-B theory, being a powerful tool for liquid state theory, has not received much attention in thermodynamic literature, as it deserves. Only few examples of practical application ${ }^{14-28}$ to binary mixtures can be found in which this theory has been to be used only for aqueous-alcohol ${ }^{14,18-22}$ binary mixtures and aqueous solutions containing electrolytes. ${ }^{23,24}$ To the best of our knowledge, very few studies have been made in the literature on nonaqueous binary mixtures. ${ }^{25-28}$ The main objective of the present study is to apply the K-B theory to the systems of varied nature in order to extract new information on the interactions between the species existing in these systems on molecular level. 
In this paper, the $\mathrm{K}-\mathrm{B}$ theory has been extended to binary mixtures of acetonitrile (ACN) with formamide (FA), N,N-dimethylformamide (DMF), Nmethylacetamide (NMA) and N,N-dimethylacetamide (DMA) at $298.15 \mathrm{~K}$ and at atmospheric pressure. Some new routes for predicting various parameters/terms involved in $\mathrm{K}-\mathrm{B}$ theory have also been incorporated and effectively used. The experimental data required for this purpose are taken from our previous studies. ${ }^{29,30}$

\section{Theory}

The solution theory proposed by Kirkwood and Buff $^{13}$ involves the theory of the grand ensembles on the one hand to relate compositional fluctuations to the derivatives of the chemical potentials of the components and on the other hand to relate them to the integrals of the radial distribution functions of the several type of molecular pairs present in the solution. The $\mathrm{K}-\mathrm{B}$ theory describes thermodynamic properties of a solution in the whole concentration range using the values of $G_{\alpha \beta}$, expressed as $\mathrm{K}-\mathrm{B}$ integrals, given by

$$
G_{\alpha \beta}=\int_{0}^{\infty}\left[g_{\alpha \beta}(r)-1\right] 4 \pi r^{2} \mathrm{~d} r,
$$

where $g_{\alpha \beta}(r)$ is the angle averaged pair correlation function and the integral extends over the entire range of intermolecular distances between the pair of molecules of species $\alpha$ and $\beta$. The interpretation of these parameters is best obtained by considering the product of number density, $\rho^{*}$ and $G_{\alpha \beta}$, i.e., $\rho_{\alpha}$ $G_{\alpha \beta}$. or $\rho_{\alpha}\left[g_{\alpha \beta}(r)-1\right] 4 \pi r^{2} \mathrm{~d} r$, where $\rho_{\alpha}$ is the number density of the $\alpha$ species. ${ }^{14}$ The quantity $G_{\alpha \beta}$ conveys information of the average affinity of the $\alpha$ molecules towards $\beta$ molecules and vice-versa. In the present study we have incorporated a new method, in the inversion procedure proposed by Ben-Naim, ${ }^{14}$ for the computation of partial vapour pressures of the mixtures for which these vapour pressure data are not available. The composition dependence of $G_{\alpha \beta}$ values provides valuable insight into the molecular structure and nature of interactions in the multi-component liquid mixture.

\subsection{Inversion procedure to compute $G_{\alpha \beta}$ 's}

The K-B equations ${ }^{13,14}$ for the binary mixture of species $A$ and $B$ can be written as

$$
\begin{aligned}
& \eta=\rho_{\mathrm{A}}+\rho_{\mathrm{B}}+\rho_{\mathrm{A}} \rho_{\mathrm{B}}\left(G_{\mathrm{AA}}+G_{\mathrm{BB}}-2 G_{\mathrm{AB}}\right), \\
& \xi=1+\rho_{\mathrm{A}} G_{\mathrm{AA}}+\rho_{\mathrm{B}} G_{\mathrm{BB}}+\rho_{\mathrm{A}} \rho_{\mathrm{B}}\left(G_{\mathrm{AA}} G_{\mathrm{BB}}-G_{\mathrm{AB}}^{2}\right),
\end{aligned}
$$

where $\eta$ and $\xi$ are constants, $\rho_{\mathrm{A}}$ and $\rho_{\mathrm{B}}$ are the number densities of $A$ and $B$, respectively. The isothermal compressibility, $k_{\mathrm{T}}$, the partial molar volumes, $\bar{V}_{\mathrm{m}, \mathrm{A}}$ and $\bar{V}_{\mathrm{m}, \mathrm{B}}$ of the two components and derivatives of the chemical potentials are given by

$$
\begin{aligned}
& k_{\mathrm{T}}=\xi / k T \eta, \\
& \bar{V}_{\mathrm{m}, \mathrm{A}}=\left[1+\rho_{\mathrm{B}}\left(G_{\mathrm{BB}}-G_{\mathrm{AB}}\right)\right] / \eta, \\
& \bar{V}_{\mathrm{m}, \mathrm{B}}=\left[1+\rho_{\mathrm{A}}\left(G_{\mathrm{AA}}-G_{\mathrm{AB}}\right)\right] / \eta, \\
& \mu_{\mathrm{AA}}=\rho_{\mathrm{B}} k T / \rho_{\mathrm{A}} \eta V, \\
& \mu_{\mathrm{BB}}=\rho_{\mathrm{A}} k T / \rho_{\mathrm{B}} \eta V, \\
& \mu_{\mathrm{AB}}=\mu_{\mathrm{BA}}=-k T / \eta V,
\end{aligned}
$$

where $k$ is the Boltzmann constant, $T$ is the absolute temperature and $\mu_{\alpha \beta}$ is given by

$$
\mu_{\alpha \beta}=\left(\frac{\partial \mu_{\alpha}}{\partial N_{\beta}}\right)_{T, p, N_{\alpha}} .
$$

We have three thermodynamic relations between the number densities, chemical potentials and partial molar volumes of the two components of the mixture, given as

$$
\begin{aligned}
& \rho_{\mathrm{A}} \mu_{\mathrm{AA}}+\rho_{\mathrm{B}} \mu_{\mathrm{AB}}=0, \\
& \rho_{\mathrm{A}} \mu_{\mathrm{AB}}+\rho_{\mathrm{B}} \mu_{\mathrm{BB}}=0, \\
& \rho_{\mathrm{A}} \bar{V}_{\mathrm{m}, \mathrm{A}}+\rho_{\mathrm{B}} \bar{V}_{\mathrm{m}, \mathrm{B}}=1 .
\end{aligned}
$$

Therefore, we have three independent equations in the three independent unknown $G_{\alpha \beta}$ 's. The derivatives of the chemical potentials have been obtained using the vapour pressure data, assuming that the vapour above the mixture at room temperature may be treated as an ideal gas. Thus, for component $A$, we can write

$$
\mu_{\mathrm{A}}=\mu_{\mathrm{A}}^{\mathrm{o}}+k T \ln P_{\mathrm{A}},
$$


where $P_{\mathrm{A}}$ is the partial pressure of component $A$ over the given mixture of $A$ and $B$. If $x_{\mathrm{A}}$ is the mole fraction of $A$ in the mixture, then we get the relation

$$
x_{\mathrm{A}}\left(\frac{\partial p_{\mathrm{A}}}{\partial x_{\mathrm{A}}}\right)=\frac{\rho^{*}}{\eta} .
$$

The number density, $\rho^{*}$, of the mixture is calculated from the partial molar volumes, $\bar{V}_{\mathrm{m}, \mathrm{A}}$ and $\bar{V}_{\mathrm{m}, \mathrm{B}}$ of the components $A$ and $B$, respectively, in the mixtures.

$$
\rho^{*}=\rho_{\mathrm{A}}+\rho_{\mathrm{B}}=\left(x_{\mathrm{A}} \bar{V}_{\mathrm{m}, \mathrm{A}}+x_{\mathrm{B}} \bar{V}_{\mathrm{m}, \mathrm{B}}\right)^{-1} .
$$

The values of $\bar{V}_{\mathrm{m}, \mathrm{A}}$ and $\bar{V}_{\mathrm{m}, \mathrm{B}}$ in the mixtures are calculated from the experimental density data by using the procedure described elsewhere. ${ }^{30}$

From (15) we can obtain $\eta$ from the data on partial vapour pressures of either $A$ or $B$ in the entire composition range. The partial vapour pressures are calculated from the activity coefficients, which are related to the excess Gibbs free energy of the mixture. The excess free energy of mixtures is given as

$$
G^{\mathrm{E}}=H^{\mathrm{E}}-T S^{\mathrm{E}} .
$$

The excess enthalpies, $H^{\mathrm{E}}$ and excess entropies, $-S^{\mathrm{E}}$ are calculated from the internal pressures, $\pi_{i}$ and free volumes, $V_{f}$ of the mixtures by using the modified relations proposed by Hildebrand et al. ${ }^{31,32}$

$$
\begin{aligned}
& H^{\mathrm{E}}=\pi_{i} V_{\mathrm{m}}-\left[x_{\mathrm{A}} \pi_{i, \mathrm{~A}} V_{\mathrm{m}, \mathrm{A}}+x_{\mathrm{B}} \pi_{i, \mathrm{~B}} V_{\mathrm{m}, \mathrm{B}}\right], \\
& -S^{\mathrm{E}}=R\left[x_{\mathrm{A}} \ln V_{\mathrm{f}, \mathrm{A}}+x_{\mathrm{B}} \ln V_{\mathrm{f}, \mathrm{B}}-\ln V_{\mathrm{f}, \mathrm{m}}\right],
\end{aligned}
$$

where $\pi_{i}$ of the mixtures are calculated using the thermodynamic equation of state

$$
\pi_{i}=\left(\frac{\partial E}{\partial V}\right)_{T}=T\left(\frac{\partial P}{\partial T}\right)_{V}-P=T\left(\frac{\alpha_{p}}{k_{T}}\right)-P,
$$

where $\alpha_{\mathrm{p}}$ is the isobaric expansivity of the mixture evaluated from temperature dependence of density data. For most of the liquids, the thermal pressure coefficient multiplied by absolute temperature, i.e. $T\left(\alpha_{\mathrm{p}} / k_{\mathrm{T}}\right)$ is very high so that the external pressure $P$ becomes negligible in comparison, ${ }^{33,34}$ therefore it may be neglected in the (20) in the present calculations. The $V_{\mathrm{f}}$ of the mixtures are calculated from the relation $^{31,32}$

$$
V_{\mathrm{f}}=\frac{R T}{\left(P+\pi_{i}\right)},
$$

since $P$ is very small as compared to $\pi_{i}$, it has been neglected in the (21) in the present calculations. The systems are assumed to be 'regular' mixtures, for which $G^{\mathrm{E}}$ are given by

$$
G^{\mathrm{E}}=x_{\mathrm{A}} x_{\mathrm{B}} N w,
$$

where $w$ is a constant computed from (22), which may depends on temperature but is independent of composition. The activity coefficients in a regular mixture are given by

$$
\ln \gamma_{i}=\left(1-x_{i}\right)^{2} w / k T \text {. }
$$

The partial vapour pressures of the components in the mixtures are calculated using the activity coefficients. Using the mole fraction dependence of partial vapour pressure of either $A$ or $B, \eta$ over the entire composition range can be easily obtained from (15). The values of $\xi$ are evaluated from (4), in which the isothermal compressibility, $\kappa_{\mathrm{T}}$, is calculated using the well-known thermodynamic relation

$$
k_{\mathrm{T}}=k_{\mathrm{s}}+\frac{T V \alpha_{T}^{2}}{C_{\mathrm{p}}}
$$

where $k_{\mathrm{s}}$ is isentropic compressibility and $C_{\mathrm{p}}$ is the heat capacity. The $C_{\mathrm{p}}$ values for the mixtures have been calculated by using the relation

$$
C_{\mathrm{p}}=x_{\mathrm{A}} C_{\mathrm{p}, \mathrm{A}}+x_{\mathrm{B}} C_{\mathrm{p}, \mathrm{B}} .
$$

Using the values of $\eta, \xi, \bar{V}_{\mathrm{m}, \mathrm{A}}$ and $\bar{V}_{\mathrm{m}, \mathrm{B}}$, the $G_{\mathrm{AB}}$ is calculated using the relation

$$
\bar{V}_{\mathrm{m}, \mathrm{A}} \bar{V}_{\mathrm{m}, \mathrm{B}}=\left(\xi-\eta G_{\mathrm{AB}}\right) / \eta^{2} .
$$

Once $G_{\mathrm{AB}}$ is obtained, (5) and (6) are used to calculate $G_{\mathrm{AA}}$ and $G_{\mathrm{BB}}$.

Another quantity proposed by Ben-Naim, ${ }^{14} \Delta_{\mathrm{AB}}$, which is a measure of the 'degree of similarity' between the two components of the mixture, has also been calculated by using the following equation

$$
\Delta_{\mathrm{AB}}=G_{\mathrm{AA}}+G_{\mathrm{BB}}-2 G_{\mathrm{AB}} .
$$

The condition $\Delta_{\mathrm{AB}}=0$ signifies symmetrical ideal solutions. The magnitude of $\Delta_{\mathrm{AB}}$ can be used to indicate the extent of deviation from ideal behaviour.

The above procedure has been used to calculate the $\mathrm{K}-\mathrm{B}$ parameters for $\mathrm{ACN}+\mathrm{FA}$, + DMF, + NMA and + DMA binary mixtures directly from ultrasonic speed and density data at $298 \cdot 15 \mathrm{~K}$. 
Table 1. Values of $\rho, u, p, k_{\mathrm{s}}, k_{\mathrm{T}}, \alpha_{\mathrm{p}}$, and $C_{\mathrm{p}}$ for pure liquids at $298 \cdot 15 \mathrm{~K}$ used in the calculation of $\mathrm{K}-\mathrm{B}$ parameters.

\begin{tabular}{lrrrrrrr}
\hline Liquid & $\begin{array}{c}\rho \\
\left(\mathrm{kg} \mathrm{m}^{-3}\right)\end{array}$ & $\begin{array}{c}u \\
\left(\mathrm{~m} \mathrm{~s}^{-1}\right)\end{array}$ & $\begin{array}{c}p \\
\left(\mathrm{~N} \mathrm{~m}^{-2}\right)\end{array}$ & $\begin{array}{c}k_{\mathrm{s}} \\
\left(10^{-10} \mathrm{~m}^{2} \mathrm{~N}^{-1}\right)\end{array}$ & $\begin{array}{r}k_{\mathrm{T}} \\
\left(10^{-10} \mathrm{~m}^{2} \mathrm{~N}^{-1}\right)\end{array}$ & $\begin{array}{c}\alpha_{\mathrm{p}} \\
\left(10^{-3} \mathrm{~K}^{-1}\right)\end{array}$ & $\begin{array}{c}C_{\mathrm{p}} \\
\left(\mathrm{J} \mathrm{mol}^{-1}\right)\end{array}$ \\
\hline ACN & $776 \cdot 6$ & $1282 \cdot 9$ & $11840 \cdot 36$ & $7 \cdot 822$ & $11 \cdot 116$ & $1 \cdot 372$ & $90 \cdot 03$ \\
FA & $1129 \cdot 0$ & $1601 \cdot 0$ & $66 \cdot 66$ & $3 \cdot 456$ & $4 \cdot 118$ & $0 \cdot 775$ & $107 \cdot 8$ \\
DMF & $944 \cdot 6$ & $1468 \cdot 3$ & $493 \cdot 29$ & $5 \cdot 048$ & $6 \cdot 575$ & $0 \cdot 999$ & $150 \cdot 8$ \\
NMA & $950 \cdot 1$ & $1398 \cdot 8$ & $127 \cdot 99$ & $5 \cdot 356$ & $6 \cdot 379$ & $0 \cdot 874$ & $170 \cdot 5$ \\
DMA & $936 \cdot 5$ & $1462 \cdot 6$ & $173 \cdot 32$ & 4.992 & $6 \cdot 426$ & $0 \cdot 894$ & $154 \cdot 5$ \\
\hline
\end{tabular}

Table 2. Values of $\rho, u, \rho^{*}, H^{\mathrm{E}}, T S^{\mathrm{E}}, \ln \left(P_{\mathrm{A}}\right), \eta, G_{\mathrm{AB}}, G_{\mathrm{AA}}, G_{\mathrm{BB}}$ and $\Delta_{\mathrm{AB}}$ for $\mathrm{ACN}+$ amide mixtures at $298 \cdot 15 \mathrm{~K}$.

\begin{tabular}{|c|c|c|c|c|c|c|c|c|c|c|c|}
\hline \multirow[b]{2}{*}{$x_{\mathrm{A}}$} & \multirow{2}{*}{$\begin{array}{c}\rho \\
\left(\mathrm{kg} \mathrm{m}^{-3}\right)\end{array}$} & \multirow{2}{*}{$\begin{array}{c}u \\
\left(\mathrm{~m} \mathrm{~s}^{-1}\right)\end{array}$} & \multirow{2}{*}{$\begin{array}{c}\rho^{*} \\
\left(\mathrm{~m}^{-3}\right)\end{array}$} & \multirow{2}{*}{$\begin{array}{c}H^{\mathrm{E}} \\
\left(\mathrm{J} \mathrm{mol}^{-3}\right)\end{array}$} & \multirow{2}{*}{$\begin{array}{c}T S^{\mathrm{E}} \\
\left(\mathrm{J} \mathrm{mol}^{-3}\right)\end{array}$} & \multirow[b]{2}{*}{$\ln \left(p_{\mathrm{A}}\right)$} & \multirow{2}{*}{$\begin{array}{c}\eta \\
\left(m^{-3}\right)\end{array}$} & $G_{\mathrm{AB}}$ & $G_{\mathrm{AA}}$ & $G_{\mathrm{BB}}$ & $\Delta_{\mathrm{AB}}$ \\
\hline & & & & & & & & \multicolumn{4}{|c|}{$\left(10^{-4} \mathrm{~m}^{3} \mathrm{~mol}^{-1}\right)$} \\
\hline \multicolumn{12}{|c|}{$\mathrm{ACN}+\mathrm{FA}$} \\
\hline 0.0764 & 1099.7 & $1591 \cdot 3$ & 24582 & $900 \cdot 20$ & $-105 \cdot 29$ & $6 \cdot 551$ & 52738 & $-1 \cdot 060$ & -0.574 & $7 \cdot 768$ & $9 \cdot 314$ \\
\hline $0 \cdot 1610$ & $1068 \cdot 1$ & $1581 \cdot 3$ & 24062 & $1720 \cdot 30$ & $-200 \cdot 92$ & $7 \cdot 320$ & 27450 & -0.555 & -0.509 & 0.463 & 1.064 \\
\hline $0 \cdot 2485$ & $1035 \cdot 7$ & $1564 \cdot 9$ & 23512 & $2246 \cdot 86$ & $-263 \cdot 75$ & $7 \cdot 778$ & 19847 & $-0 \cdot 404$ & -0.524 & $-0 \cdot 372$ & -0.089 \\
\hline $0 \cdot 3444$ & 999.7 & $1539 \cdot 0$ & 22894 & $2469 \cdot 78$ & $-291 \cdot 82$ & $8 \cdot 131$ & 16516 & -0.337 & -0.570 & $-0 \cdot 520$ & $-0 \cdot 415$ \\
\hline $0 \cdot 4120$ & $974 \cdot 3$ & $1516 \cdot 8$ & 22454 & $2453 \cdot 01$ & $-291 \cdot 60$ & $8 \cdot 330$ & 15564 & $-0 \cdot 318$ & $-0 \cdot 613$ & -0.522 & -0.499 \\
\hline 0.5336 & $930 \cdot 0$ & $1475 \cdot 1$ & 21671 & $2254 \cdot 70$ & $-272 \cdot 26$ & $8 \cdot 622$ & 15863 & $-0 \cdot 324$ & -0.702 & -0.469 & $-0 \cdot 524$ \\
\hline 0.6388 & $893 \cdot 0$ & $1434 \cdot 5$ & 21014 & $1884 \cdot 50$ & $-231 \cdot 91$ & 8.831 & 18842 & $-0 \cdot 383$ & -0.741 & $-0 \cdot 390$ & $-0 \cdot 364$ \\
\hline 0.7554 & $853 \cdot 4$ & 1387.9 & 20309 & $1369 \cdot 88$ & $-172 \cdot 01$ & $9 \cdot 031$ & 31901 & $-0 \cdot 646$ & -0.195 & $-0 \cdot 200$ & 0.895 \\
\hline $0 \cdot 8754$ & $814 \cdot 5$ & $1336 \cdot 9$ & 19610 & $723 \cdot 92$ & $-92 \cdot 49$ & $9 \cdot 212$ & 48896 & $-2 \cdot 997$ & $16 \cdot 123$ & -1.003 & $23 \cdot 120$ \\
\hline \multicolumn{12}{|c|}{$\mathrm{ACN}+\mathrm{DMF}$} \\
\hline $0 \cdot 1303$ & $930 \cdot 1$ & 1431.8 & 18954 & $268 \cdot 29$ & $-49 \cdot 45$ & $7 \cdot 100$ & 31243 & $-1 \cdot 261$ & $-0 \cdot 405$ & $1 \cdot 359$ & $3 \cdot 477$ \\
\hline $0 \cdot 2586$ & $914 \cdot 5$ & $1413 \cdot 6$ & 18984 & $450 \cdot 95$ & $-89 \cdot 19$ & $7 \cdot 821$ & 18402 & -0.743 & $-0 \cdot 445$ & -0.825 & $0 \cdot 217$ \\
\hline $0 \cdot 3851$ & $897 \cdot 4$ & $1393 \cdot 2$ & 19013 & $541 \cdot 56$ & $-116 \cdot 48$ & $8 \cdot 255$ & 14822 & -0.599 & -0.476 & -0.914 & $-0 \cdot 191$ \\
\hline 0.5125 & $878 \cdot 4$ & $1371 \cdot 0$ & 19043 & $574 \cdot 43$ & $-133 \cdot 06$ & $8 \cdot 576$ & 13924 & -0.564 & -0.484 & -0.847 & -0.204 \\
\hline 0.5925 & $865 \cdot 2$ & $1355 \cdot 8$ & 19062 & $554 \cdot 04$ & $-135 \cdot 13$ & $8 \cdot 743$ & 14282 & -0.578 & $-0 \cdot 451$ & -0.805 & -0.099 \\
\hline 0.6899 & 847.8 & $1336 \cdot 5$ & 19085 & $503 \cdot 37$ & $-129 \cdot 59$ & $8 \cdot 922$ & 15842 & $-0 \cdot 641$ & $-0 \cdot 286$ & -0.770 & 0.226 \\
\hline 0.7736 & $831 \cdot 1$ & $1318 \cdot 8$ & 19105 & 424.83 & $-113 \cdot 87$ & $9 \cdot 060$ & 18837 & -0.761 & 0.214 & -0.766 & 0.970 \\
\hline 0.8522 & $813 \cdot 9$ & $1301 \cdot 2$ & 19124 & $321 \cdot 29$ & $-88 \cdot 62$ & $9 \cdot 179$ & 24872 & $-1 \cdot 001$ & 1.981 & -0.807 & $3 \cdot 176$ \\
\hline 0.9359 & $793 \cdot 8$ & $1281 \cdot 4$ & 19144 & $178 \cdot 12$ & $-48 \cdot 39$ & $9 \cdot 295$ & 43782 & -1.753 & $15 \cdot 740$ & $-1 \cdot 016$ & $18 \cdot 230$ \\
\hline \multicolumn{12}{|c|}{$\mathrm{ACN}+\mathrm{NMA}$} \\
\hline 0.1232 & $940 \cdot 3$ & $1396 \cdot 5$ & 18981 & 738.54 & $-75 \cdot 40$ & $7 \cdot 042$ & 31751 & $-1 \cdot 257$ & $-0 \cdot 402$ & $1 \cdot 616$ & 3.728 \\
\hline $0 \cdot 2665$ & $922 \cdot 5$ & $1389 \cdot 6$ & 19049 & $1330 \cdot 87$ & $-144 \cdot 17$ & $7 \cdot 853$ & 17646 & -0.700 & $-0 \cdot 452$ & -0.878 & 0.070 \\
\hline $0 \cdot 3702$ & $908 \cdot 3$ & $1384 \cdot 2$ & 19098 & $1664 \cdot 02$ & $-187 \cdot 06$ & $8 \cdot 211$ & 14860 & -0.590 & -0.479 & -0.928 & $-0 \cdot 227$ \\
\hline 0.4925 & 889.6 & $1373 \cdot 2$ & 19156 & $1811 \cdot 38$ & $-215 \cdot 56$ & $8 \cdot 531$ & 13946 & -0.555 & -0.491 & -0.856 & -0.237 \\
\hline $0 \cdot 5800$ & $874 \cdot 6$ & $1365 \cdot 1$ & 19198 & $1844 \cdot 61$ & $-227 \cdot 52$ & $8 \cdot 719$ & 14389 & -0.573 & $-0 \cdot 460$ & -0.804 & $-0 \cdot 117$ \\
\hline 0.6766 & $856 \cdot 3$ & $1353 \cdot 2$ & 19245 & 1724.94 & $-222 \cdot 79$ & 8.899 & 16152 & $-0 \cdot 643$ & $-0 \cdot 303$ & -0.763 & 0.219 \\
\hline 0.7613 & $838 \cdot 4$ & $1340 \cdot 8$ & 19286 & $1503 \cdot 84$ & $-202 \cdot 31$ & $9 \cdot 041$ & 19667 & -0.781 & $0 \cdot 194$ & -0.757 & $1 \cdot 000$ \\
\hline 0.8305 & $822 \cdot 4$ & $1327 \cdot 1$ & 19319 & $1186 \cdot 52$ & $-166 \cdot 48$ & $9 \cdot 147$ & 25792 & $-1 \cdot 021$ & 1.596 & -0.792 & $2 \cdot 846$ \\
\hline 0.9203 & $799 \cdot 5$ & $1306 \cdot 4$ & 19363 & $647 \cdot 65$ & $-96 \cdot 16$ & $9 \cdot 274$ & 52524 & $-2 \cdot 065$ & $14 \cdot 828$ & -1.059 & $17 \cdot 898$ \\
\hline \multicolumn{12}{|c|}{$\mathrm{ACN}+\mathrm{DMA}$} \\
\hline $0 \cdot 1674$ & $921 \cdot 8$ & $1443 \cdot 5$ & 18990 & $497 \cdot 24$ & $-59 \cdot 93$ & $7 \cdot 361$ & 27450 & $-1 \cdot 349$ & $-0 \cdot 371$ & $0 \cdot 102$ & $2 \cdot 429$ \\
\hline $0 \cdot 3133$ & $906 \cdot 7$ & $1426 \cdot 7$ & 19048 & 889.49 & $-109 \cdot 88$ & $8 \cdot 028$ & 17482 & -0.859 & $-0 \cdot 385$ & -0.990 & $0 \cdot 344$ \\
\hline 0.4223 & 893.8 & $1413 \cdot 7$ & 19092 & $1134 \cdot 01$ & $-143 \cdot 88$ & $8 \cdot 357$ & 15128 & -0.744 & $-0 \cdot 380$ & -0.998 & $0 \cdot 110$ \\
\hline 0.5387 & 877.9 & $1396 \cdot 1$ & 19139 & $1234 \cdot 82$ & $-166 \cdot 07$ & 8.633 & 14407 & -0.708 & -0.331 & -0.944 & 0.141 \\
\hline 0.6379 & $862 \cdot 2$ & 1377.9 & 19179 & $1191 \cdot 55$ & $-170 \cdot 88$ & $8 \cdot 830$ & 14877 & -0.731 & $-0 \cdot 195$ & -0.909 & 0.359 \\
\hline 0.7236 & $846 \cdot 7$ & $1361 \cdot 2$ & 19214 & 1101.98 & $-166 \cdot 31$ & 8.979 & 16227 & -0.798 & $0 \cdot 126$ & -0.902 & 0.820 \\
\hline 0.8071 & $829 \cdot 0$ & $1342 \cdot 2$ & 19248 & $914 \cdot 15$ & $-145 \cdot 17$ & $9 \cdot 112$ & 18905 & -0.929 & $1 \cdot 021$ & -0.930 & 1.950 \\
\hline 0.8776 & $812 \cdot 0$ & $1323 \cdot 8$ & 19277 & 673.47 & $-111 \cdot 86$ & $9 \cdot 215$ & 23234 & $-1 \cdot 142$ & $3 \cdot 518$ & -1.006 & 4.796 \\
\hline 0.9424 & $794 \cdot 3$ & $1303 \cdot 7$ & 19303 & 358.64 & $-62 \cdot 43$ & $9 \cdot 304$ & 31295 & -1.538 & 14.631 & $-1 \cdot 178$ & $16 \cdot 530$ \\
\hline
\end{tabular}




\section{Results and discussion}

The values of $\mathrm{K}-\mathrm{B}$ parameters for the abovementioned binary systems have been calculated as a function of mole fraction, $x_{\mathrm{A}}$ of component $A(\mathrm{ACN})$ at $298.15 \mathrm{~K}$. The values of various parameters of pure liquids used in the calculations are listed in
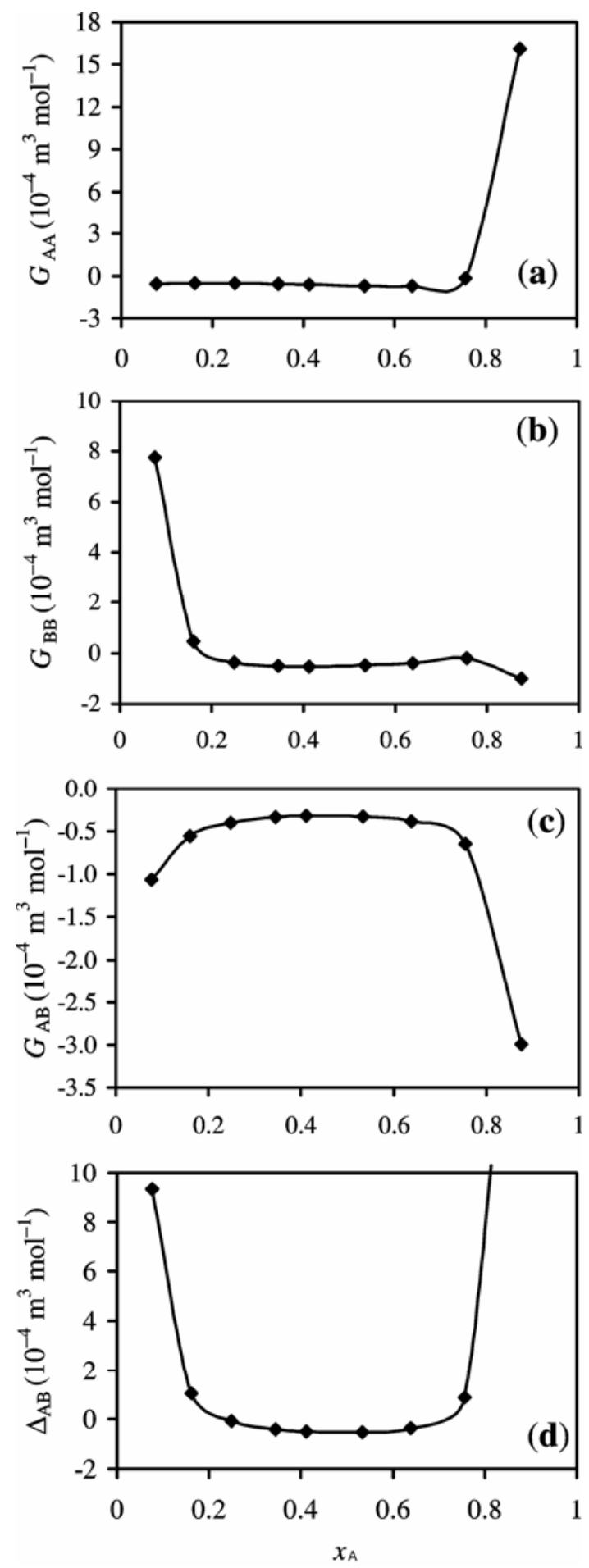

Figure 1. Plots of $G_{\mathrm{AA}}, G_{\mathrm{BB}}, G_{\mathrm{AB}}$ and $\Delta_{\mathrm{AB}}$ against mole fraction, $x_{\mathrm{A}}$ of ACN for ACN + FA mixtures at $298 \cdot 15 \mathrm{~K}$. table 1. The values of $\mathrm{K}-\mathrm{B}$ parameters, viz. $G_{\mathrm{AA}}$, $G_{\mathrm{BB}}, G_{\mathrm{AB}}$ and $\Delta_{\mathrm{AB}}$ along with some other parameters for the binary systems investigated as function of mole fraction, $x_{\mathrm{A}}$ of ACN for each system, are listed in table 2 . The variations of $G_{\mathrm{AA}}, G_{\mathrm{BB}}, G_{\mathrm{AB}}$ and $\Delta_{\mathrm{AB}}$
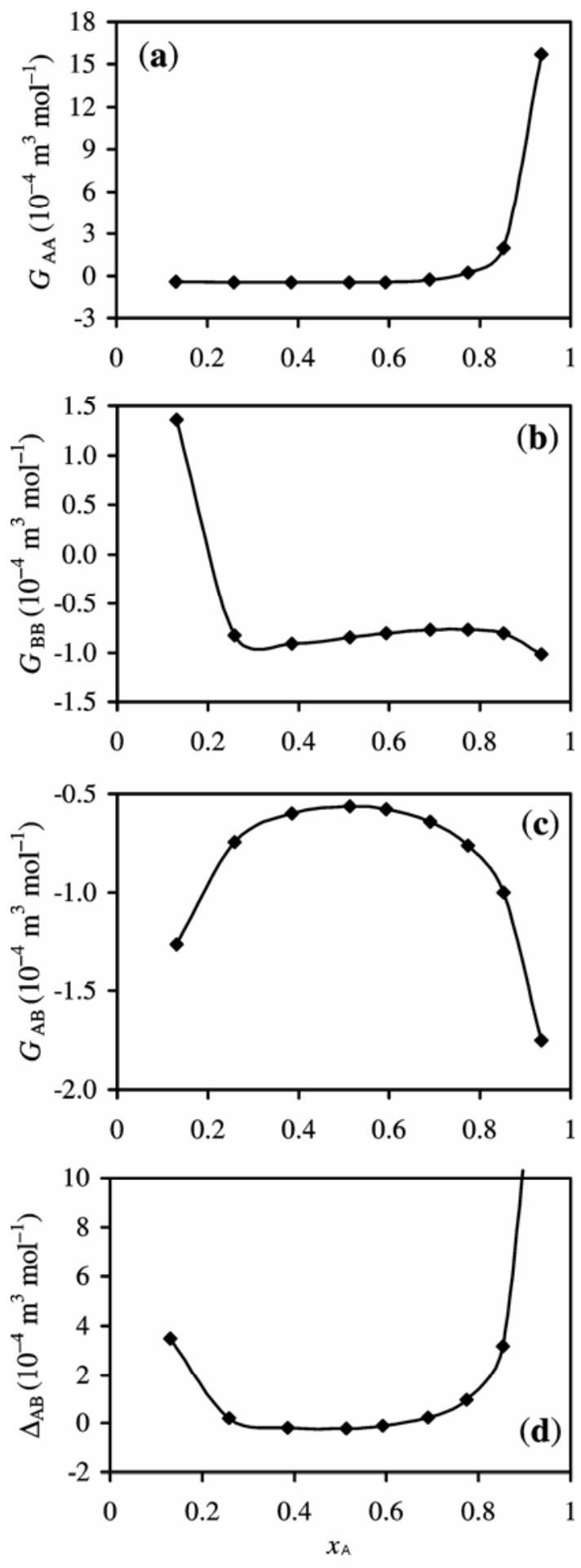

Figure 2. Plots of $G_{\mathrm{AA}}, G_{\mathrm{BB}}, G_{\mathrm{AB}}$ and $\Delta_{\mathrm{AB}}$ against mole fraction, $x_{\mathrm{A}}$ of $\mathrm{ACN}$ for $\mathrm{ACN}+\mathrm{DMF}$ mixtures at $298 \cdot 15 \mathrm{~K}$. 
against mole fraction, $x_{\mathrm{A}}$ of $\mathrm{ACN}$ for each mixture are shown graphically in figures $1-4$. The low values excess entropy $\left(S^{\mathrm{E}} \approx 0\right)$ obtained for these systems (table 2) clearly indicate that these mixtures can be considered as regular solutions. ${ }^{31,32}$
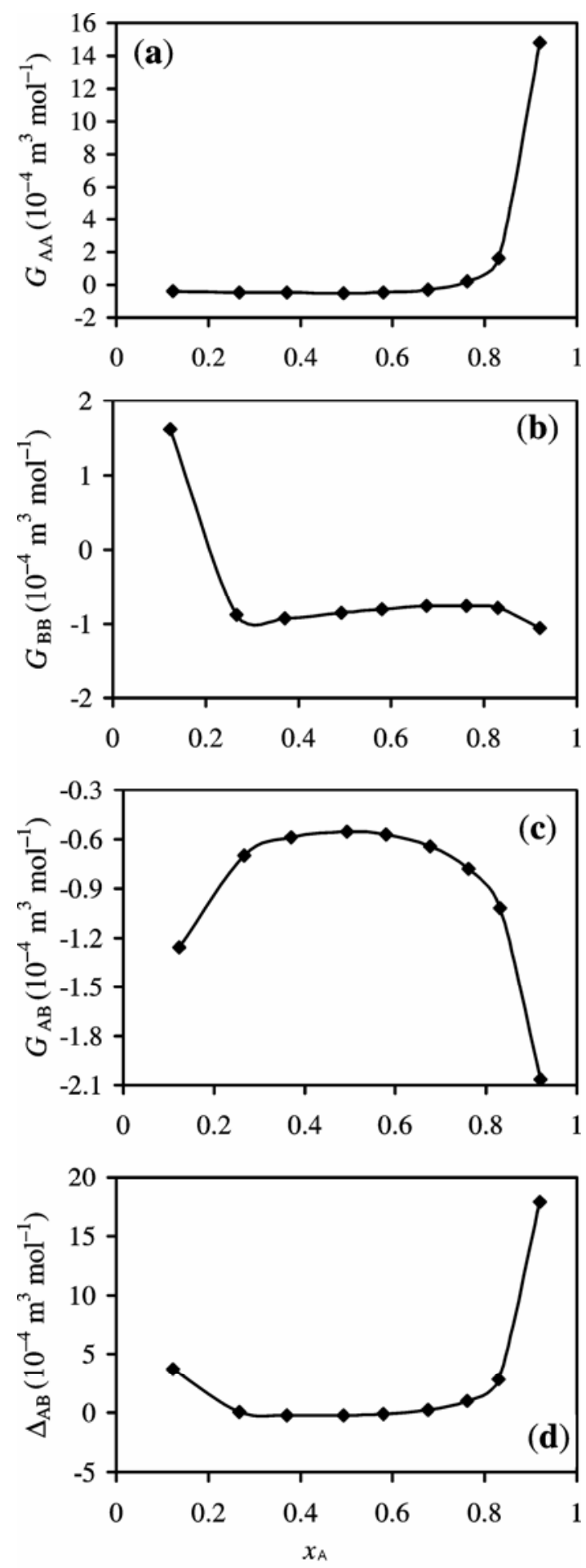

Figure 3. Plots of $G_{\mathrm{AA}}, G_{\mathrm{BB}}, G_{\mathrm{AB}}$ and $\Delta_{\mathrm{AB}}$ against mole fraction, $x_{\mathrm{A}}$ of $\mathrm{ACN}$ for $\mathrm{ACN}+\mathrm{NMA}$ mixtures at $298 \cdot 15 \mathrm{~K}$.
Figure 1(a) shows the behaviour of ACN-ACN affinity over the entire composition range. Table 2 and figure 1(a) indicate that $G_{\mathrm{AA}}$ values are negative and initially decreases with increase in mole fraction up to $x_{\mathrm{A}} \approx 0.55$ and then increases after this point and finally become positive, suggesting decreasing correlation between ACN molecules and this correla-
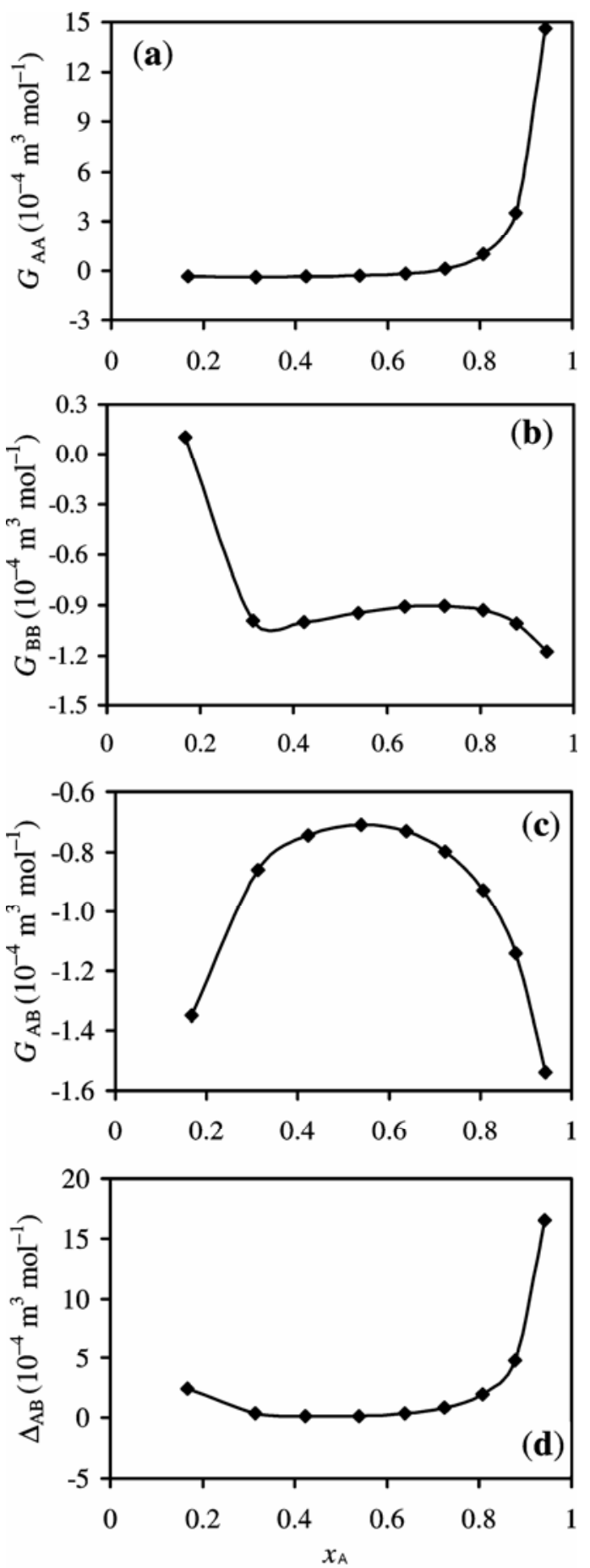

Figure 4. Plots of $G_{\mathrm{AA}}, G_{\mathrm{BB}}, G_{\mathrm{AB}}$ and $\Delta_{\mathrm{AB}}$ against mole fraction, $x_{\mathrm{A}}$ of $\mathrm{ACN}$ for $\mathrm{ACN}+\mathrm{DMA}$ mixtures at $298 \cdot 15 \mathrm{~K}$. 
tion increases after $x_{\mathrm{A}} \approx 0.55$ may be due to strong dipole-dipole interactions between ACN molecules at higher ACN concentration. Figure 1(b) indicates that $G_{\mathrm{BB}}$ values are positive and initially decrease to negative values with increase in mole fraction till $x_{\mathrm{A}} \approx 0.22$ and then increases slightly after this point, suggesting decreasing correlation between FA molecules on increasing the amount of added ACN in the mixture, which leads to breaking of the associations present between FA molecules. Figure 1(c) indicates that that $G_{\mathrm{AB}}$ values are negative and increases initially and exhibit a maximum at $x_{\mathrm{A}} \approx 0.42$ and then decrease with increase in mole fraction of $\mathrm{ACN}$, suggesting increasing correlation between $\mathrm{ACN}$ and FA molecules on increasing the amount of $\mathrm{ACN}$ in the mixture till $x_{\mathrm{A}} \approx 0.42$, which then decreases with further increase in mole fraction of ACN. This behaviour is in agreement with the conclusions drawn in our earlier study, ${ }^{29,30}$ wherein $V_{\mathrm{m}}^{\mathrm{E}}$ and $\Delta k_{\mathrm{s}}$ vs $x_{\mathrm{A}}$ curves exhibit a minimum at $x_{\mathrm{A}} \approx 0.42$, indicating maximum interaction between ACN and FA molecules near this composition. Also, $\Delta_{\mathrm{AB}}$ values (figure 1(d)) are positive and decrease initially to negative values exhibiting a minimum at $x_{\mathrm{A}} \approx 0.42$ and then again increase to positive values, indicating the dissimilarity between the unlike molecules in the mixtures and negative deviations from the ideal behaviour. ${ }^{14}$

Figures $2-4$ also depict similar trends in $G_{\mathrm{AA}}, G_{\mathrm{BB}}$, $G_{\mathrm{AB}}$ and $\Delta_{\mathrm{AB}}$ values against mole fraction, $x_{\mathrm{A}}$ for $\mathrm{ACN}+\mathrm{DMF} / \mathrm{NMA} / \mathrm{DMA}$ mixtures as shown by ACN + FA mixtures. A close perusal of table 2 indicates that the magnitude of $G_{\mathrm{AB}}$ varies in the order: FA $>$ NMA $>$ DMA $>$ DMF, suggesting that the affinity or interactions between the ACN and amide molecules follow the order: $\mathrm{FA}>\mathrm{NMA}>\mathrm{DMA}>$ DMF, which is in agreement with the conclusions drawn regarding the intermolecular interactions from the trends exhibited by the excess functions of these mixtures. ${ }^{29,30}$

The work on extending this procedure for calculation of $\mathrm{K}-\mathrm{B}$ integrals to a variety of other binary mixture containing combination of nonpolar-nonpolar, polar-nonpolar and polar-polar liquids is in progress. We feel that in future this method may prove to be a valuable tool for the calculation of $\mathrm{K}-\mathrm{B}$ integrals for all mixtures, in general.

\section{Acknowledgement}

The author is thankful to Dr IS Bakshi, Principal, Dyal Singh College (University of Delhi),
New Delhi for providing facilities and encouragement.

\section{References}

1. Iloukhani H, Zoorasna Z and Soleimani R 2005 Phys. Chem. Liq. $\mathbf{4 3} 391$

2. George J and Sastry N V 2004 Fluid Phase Equilib. 216307

3. Giner B, Artigas H, Carrion A, Lafuente C and Royo F M 2003 J. Mol. Liq. 108303

4. Nain A K 2006 J. Solution Chem. 351417

5. Nain A K 2007 Phys. Chem. Liq. 45371

6. Nain A K 2007 J. Chem. Thermodyn. 39462

7. Nain A K 2008 J. Mol. Liq. 140108

8. Nain A K 2008 Fluid Phase Equilib. 26546

9. Ali A, Nain A K, Chand D and Ahmad R 2006 Bull. Chem. Soc. Jpn. 79702

10. Ali A and Nain A K 2002 Bull. Chem. Soc. Jpn. 75 681

11. Oswal S L, Maisuria M M and Gardas R L $2003 \mathrm{~J}$. Mol. Liq. 108199

12. Gonzalez J A, Riesco N, Mozo I, De La Fuente I G and Cobos J C 2007 Ind. Eng. Chem. Res. 46 1350

13. Kirkwood J G and Buff F P 1951 J. Chem. Phys. 19 774

14. Ben-Naim A 1977 J. Chem. Phys. 674884

15. Shuglin I L and Ruckenstein E 2006 J. Phys. Chem. B110 12707

16. Perera A, Sokolic F, Almasy L and Koga Y $2006 J$. Chem. Phys. 124 124575-1

17. Gonzalez J A, Mozo I, Villa S, Riesco N, De La Fuente, I G and Cobos J C 2006 J. Solution Chem. 35 787

18. Donkersloot M C A 1979 J. Solution Chem. 8293

19. Newman K E 1994 Chem. Soc. Rev. 2331

20. Newman K E 1988 J. Chem. Soc., Faraday Trans. 84 3885

21. Vergara A, Paduano L, Capuano F and Sartorio R 2002 Phys. Chem. Chem. Phys. 44716

22. Roux A H and Desnoyers J E 1987 Proc. Indian Acad. Sci. (Chem. Sci.) $\mathbf{9 8} 435$

23. Banerjee D, Laha A K, Chatterjee P and Bagchi S 1995 J. Solution Chem. 24301

24. Covington A K and Newman K E $1988 \mathrm{~J}$. Chem. Soc., Faraday Trans. 841393

25. Pandey J D and Verma R 2001 Chem. Phys. 270429

26. Guha A and Ghosh N K 2006 Indian J. Chem. A45 593

27. Matteoli E 1997 J. Phys. Chem. B101 9800

28. Marcus Y 2006 J. Solution Chem. 35251

29. Nain A K 2006 Bull. Chem. Soc. Jpn. 791688

30. Nain A K 2006 J. Chem. Thermodyn. 381362

31. Hildebrand J H and Scott R L 1962 Regular solutions (New Jersey: Prentice Hall)

32. Hildebrand J H 1947 J. Chem. Phys. 15225

33. Dack M R J 1975 Chem. Soc. Rev. 4211

34. Pal A and Kumar H 2004 Indian J. Chem. A43 28 